\title{
Numerical simulation on flow and heat transfer characteristics of supercritical fluids in mini-channels
}

\author{
A. N. Oumer, ${ }^{1,}{ }^{*}$, N. T. Rao ${ }^{2}$, F. Basrawi ${ }^{3}$, H. Ibrahim ${ }^{4}$ \\ 1, 2, 3, 4 Faculty of Mechanical Engineering, University of Malaysia Pahang, 26600 Pekan, Pahang, \\ Malaysia
}

\section{Index Terms}

Supercritical Fluid

Computational Fluid Dynamics

Heat Transfer

Simulation.

Received: 21 May 2016

Accepted: 1 June 2015

Published: 21 June 2016

\begin{abstract}
This paper investigated the flow and heat transfer characteristics of supercritical carbon dioxide (SC-CO2) and supercritical water $\left(\mathrm{SC}-\mathrm{H}_{2} \mathrm{O}\right)$ in horizontal microchannels using a CFD approach. A straight, circular pipe of stainless steel with internal and external radii of, and, respectively, and a heated length of $55 \mathrm{~mm}$ were considered. For the simulation, carbon dioxide and water at supercritical pressures of 9.5 MPa and 22.07 MPa were used, while uniform heat was applied on the outer surface of the tube. The thermodynamic properties for both fluids were obtained from the NIST Chemistry Webbook. The simulated temperature and heat transfer coefficient variation was compared with experimental results from the literature. In general, the simulation results were close to the experiment. Both the simulation and experimental results showed that the wall temperature increased along the tube length. As expected, the heat transfer coefficient values for both supercritical fluids decreased as the length of the tube. This was because a maximum and dominant convection heat transfer occurred at the entrance of the heated section of the pipe. This study could assist in decisions regarding the use of supercritical fluids in industries that involve heat transfer.
\end{abstract}

(c) 2016 The Author(s). Published by TAF Publishing.

\section{INTRODUCTION}

Supercritical fluid can be defined as a substance that has temperature and pressure above the critical points, where we cannot distinguish the liquid and gas phases. Supercritical Carbon dioxide $\left(\mathrm{SC}-\mathrm{CO}_{2}\right)$ and supercritical water $\left(\mathrm{SC}-\mathrm{H}_{2} \mathrm{O}\right)$ are the two common supercritical fluids being utilized in many engineering fields such as materials preparation [1], nuclear reactor [2], [3] solar collector [4],

\footnotetext{
${ }^{*}$ Corresponding author: A. N. Oumer

E-mail: Ahmnur99@gmail.com
}

refrigeration and air-conditioning systems $[5,6]$ and analytical fields [7], [9]. Carbon dioxide has a critical temperature and pressure of $304 \mathrm{~K}$ and $7.38 \mathrm{MPa}$ respectively whereas water has a critical temperature of $647.1 \mathrm{~K}$ and critical pressure of $22.1 \mathrm{MPa}$. At supercritical stage, the fluids have no surface tension as there is no liquid and gas boundary.

Carbon dioxide and water at supercritical phase are known for their heat transfer enhancing and degrading behaviors. Significant changes in thermophysical properties of $\mathrm{CO}_{2}$ and $\mathrm{H}_{2} \mathrm{O}$ at supercritical pressures influence their heat-transfer. The most significant 
properties variations occur within critical and pseudocritical points [10], [11].

Significant number of researches has been conducted to study the flow and heat transfer characteristics of supercritical $\mathrm{CO}_{2}$ and $\mathrm{H}_{2} \mathrm{O}$ [12], [15]. For instance [12] have investigated influences of some parameters on the flow and heat transfer characteristics of supercritical carbon dioxide in a vertical tube. Regarding the influence of pressure, they observed that for all pressures, the heat transfer coefficient was almost constant in the liquid-like and gas-like regions. It reached a peak value near the pseudo-critical temperature, whose value was damped with increasing pressures. Moreover, an increase in mass flux caused the heat transfer coefficient of carbon dioxide to increase due to an enhancement of turbulent diffusion for upward flows. On the other hand different phenomena were observed for the downward flow. In another research, [16] from University of Massachusetts Amherst has applied computational simulation to study heat transfer enhancement using supercritical carbon dioxide in capillary flow. Homogeneous and separated flow methods were used to study certain sections in the tube capillary. It was found out that the carbon dioxide can undergo rapid expansion at supercritical state. The concentration of the mixture can affect the pressure as well resulting that the higher the concentration, the larger the increase in critical pressure.

On the other hand, according to the study of [17], the reduced effect of hydrogen bonding decreases the SC- $\mathrm{H}_{2} \mathrm{O}^{\prime} \mathrm{s}$ solubility. Hydrogen bonding, which is a covalent bond, has relatively low intermolecular force. The density was decreased under supercritical condition, weakening the hydrogen bonding. They have conducted spectroscopic and numerical simulation studies which revealed that the number of hydrogen bonds per molecules under supercritical condition was approximately $1 / 3$ of the number at ambient temperature. More recently [18] has developed one dimensional heat transfer correlation for $\mathrm{SC}-\mathrm{H}_{2} \mathrm{O}$ in vertical tubes based on a new set of heattransfer data and the latest thermophysical properties of water using NIST [19].

However, the flow and heat transfer characteristics of supercritical fluids such as carbon dioxide and water are not fully discovered. The present study has therefore been undertaken to investigate the flow and heat transfer characteristics of $\mathrm{SC}-\mathrm{CO}_{2}$ and $\mathrm{SC}-\mathrm{H}_{2} \mathrm{O}$ using a CFD approach. In this paper we presented results for the simplest configuration of a horizontal double pipe heat exchanger with carbon dioxide and water flow in the cylinder at supercritical pressure and temperature. The density, viscosity, thermal conductivity and coefficient of heat capacity of the fluids were obtained from NIST database. Results presented for various cases for Sc-CO2 and at various temperature for $\mathrm{Sc}-\mathrm{H}_{2} \mathrm{O}$ include the bulk temperatures, the wall temperature and the thermal heat coefficient.

\section{MODEL AND SIMULATION SETUP}

\section{A. Physical Model}

Schematic of the physical model of the straight circular pipe of stainless steel of internal and external radii of , and , respectively, and a heated length of $55 \mathrm{~mm}$ is shown in Figure 1. The computational domain is simplified to be an axisymmetric plane.

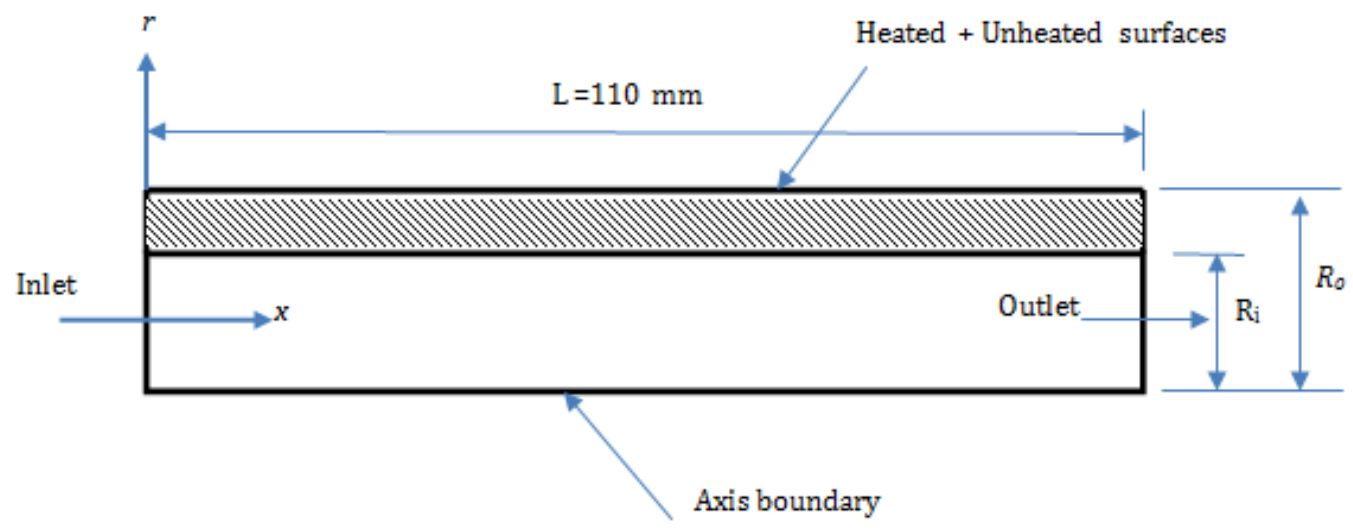

Fig. 1. Schematic of the flow geometry 
For the simulation, carbon dioxide and water at supercritical pressures of $9.5 \mathrm{MPa}$ and $22.07 \mathrm{MPa}$ respectively were considered with uniform heat applied on the outer surface of the tube. Unheated section with a length of $27.5 \mathrm{~mm}$ was used at the beginning to obtain a fully-developed flow-field prior to the heat transfer process, the middle section of $55 \mathrm{~mm}$ long is heated with a constant wall heat flux, while unheated section of $27.5 \mathrm{~mm}$ long is included at the end to avoid the effects of out-flow boundary conditions on the numerical results. The flow was driven by an externally imposed mean pressure gradient in the axial direction.

In this study, the flow field is assumed to be incompressible, steady, non-isothermal and twodimensional (2D) flow. Therefore, the conservation equations were presented in the following forms [20], [21], [22],[23]:

Mass conservation:

$$
\frac{\partial}{\partial x}\left(\rho u_{x}\right)+\frac{1}{r} \frac{\partial}{\partial r}\left(r \rho u_{r}\right)=0
$$

Momentum conservation:

$$
\frac{\partial}{\partial x}\left(\rho u_{x} u_{x}\right)+\frac{1}{r} \frac{\partial}{\partial r}\left(r \rho u_{x} u_{r}\right)=-\frac{\partial p}{\partial x}+\frac{\partial \tau_{x x}}{\partial x}+\frac{1}{r} \frac{\partial}{\partial r}\left(r \tau_{x r}\right)
$$

$\frac{\partial}{\partial x}\left(\rho u_{r} u_{x}\right)+\frac{1}{r} \frac{\partial}{\partial r}\left(r \rho u_{r} u_{r}\right)=-\frac{\partial p}{\partial r}+\frac{\partial \tau_{r x}}{\partial x}+\frac{1}{r} \frac{\partial}{\partial r}\left(r \tau_{r r}\right)$

Energy conservation:

$$
\rho C_{p} u_{x} \frac{\partial T}{\partial x}+\rho C_{p} u_{r} \frac{\partial T}{\partial r}=\frac{\partial}{\partial x}\left(k \frac{\partial T}{\partial x}\right)+\frac{1}{r} \frac{\partial}{\partial r}\left(r k \frac{\partial T}{\partial r}\right)
$$

where $u, \rho, p, T, \tau, C_{p}$, and $k$ are the velocity, density, pressure, temperature, shear stress, thermal heat capacity, and thermal conductivity respectively. The terms $x$ and $r$ represent the axial and radial directions respectively. In the present numerical study of the supercritical heat transfer of fluids, given the high wall heat fluxes and the strong thermophysical property variations in the near-wall region, the $k-\varepsilon$ turbulent model was employed for the internal turbulent flow and heat transfer calculations. Structured grid arrangement was used to define the variables and, due to its good accuracy, QUICK technique was used to approximate the convection terms in the momentum equation. Moreover, coupled scheme was used to couple the pressure and velocity terms.

\section{B. Boundary Conditions And Thermophysical Properties}

In this study, the commercial computational fluid dynamics (CFD) software called Ansys FLUENT was used. The inlet velocity and supercritical pressure boundary

TABLE 1

BOUNDARY CONDITIONS AND THERMOPHYSICAL PROPERTIES OF SUPERCRITICAL CARBON DIOXIDE USED IN THE SIMULATION $[11,19]$

\begin{tabular}{ccccccccc}
\hline \hline Test ID & $\begin{array}{c}\text { Inlet } \\
\text { Pressure } \\
(\mathrm{Mpa})\end{array}$ & $\begin{array}{c}\text { Inlet } \\
\text { Temp } \\
\left({ }^{\circ} \mathrm{C}\right)\end{array}$ & $\begin{array}{c}\dot{\boldsymbol{m}} \\
(\mathrm{kg} / \mathrm{hr})\end{array}$ & $\boldsymbol{\rho}$ & $\mathrm{C}_{\mathrm{p}}$ & $\mathrm{k}$ & $\boldsymbol{\mu}$ & $\begin{array}{c}\text { Wall Heat Flux } \\
\left(\mathrm{kW} / \mathrm{m}^{2}\right)\end{array}$ \\
\hline & & & & & & & & \\
Case01 & 9.5 & 32.7 & 1.47 & 725.69 & 3944 & 0.0793 & $5.94 \mathrm{E}-05$ & 31 \\
Case02 & 9.5 & 51 & 1.47 & 319.23 & 4315 & 0.0444 & $2.48 \mathrm{E}-05$ & 31 \\
Case03 & 9.5 & 39.6 & 1.47 & 591.84 & 3237 & 0.0710 & $4.40 \mathrm{E}-05$ & 31 \\
\hline \hline
\end{tabular}

conditions were used to set the incoming flow properties while appropriate gauge pressure boundary conditions were used at the outlet to describe a fully-developed flow at the mini tube. Due to symmetric nature of the tube, axisymmetric boundary conditions were defined at the tube center axis. No slip and constant heat flux boundary conditions were there for the heated section and only no slip boundary conditions for the unheated (thermally isolated tube walls) were employed to describe a viscous flow. In the present work, the thermophysical properties 
of both carbon dioxide and water at the supercritical pressures and temperatures were obtained from National Institute of Standards and Technology (NIST) [19]. For Sc-
$\mathrm{CO}_{2}$, the boundary conditions and thermophysical property values considered in this study are tabulated in Table 1.

TABLE 2

THERMOPHYSICAL PROPERTIES OF SUPERCRITICAL WATER USED IN THE SIMULATION

\begin{tabular}{ccccccc}
\hline \hline $\begin{array}{c}\text { Inlet } \mathrm{P} \\
(\mathrm{Mpa})\end{array}$ & Inlet T $\left({ }^{\circ} \mathrm{C}\right)$ & $\begin{array}{c}\dot{\boldsymbol{m}} \\
(\mathrm{kg} / \mathrm{hr})\end{array}$ & $\boldsymbol{\rho}$ & $\mathrm{C}_{\mathrm{p}}$ & $\mathrm{k}$ & $\boldsymbol{\mu}$ \\
\hline 22.07 & 374.4 & 1.47 & 228.95 & $1.22 \mathrm{E}+05$ & 0.37045 & $3.18 \mathrm{E}-05$ \\
22.07 & 390 & 1.47 & 136.66 & $1.09 \mathrm{E}+04$ & 0.14132 & $2.70 \mathrm{E}-05$ \\
22.07 & 450 & 1.47 & 90.321 & $4.40 \mathrm{E}+03$ & 0.097512 & $2.82 \mathrm{E}-05$ \\
\hline \hline
\end{tabular}

\section{RESULTS AND DISCUSSION}

To apply the application of CFD codes to supercritical fluids and validate the simulation results, a horizontal circular steel channel was selected for validation which was studied experimentally by [11]. Simulations were performed by studying the influence of the inlet temperature on the heat transfer coefficient.

Comparisons of the inner wall temperatures and heat transfer coefficients for supercritical carbon dioxide obtained from the current simulation model against experimentally measured values from [11] are shown in Figures 2 and 3 respectively.

The inlet supercritical pressure and mass flow rates were kept constant for all the cases. The average (nominal) pressure and mass flow rate were $9.5 \mathrm{MPa}$ and $1.47 \mathrm{~kg} / \mathrm{hr}$ respectively while significantly variable temperatures were applied at the tube inlet. As can be seen from Figures 2, the simulations have the same trend with the experimental results. In Figure 2, both simulation and experimental results show that the wall temperatures increase along the length of the tube. It can also be seen from the figure that the current simulation results are close to the experiment at temperature close to pseudo-critical temperature than at high temperature. For case 01 which is at inlet temperature close to the critical temperature, the maximum wall temperature variation between the current simulation and the experimental results are relatively high at $21 \%$ maximum error. On the other hand, at high inlet temperature (Case02) the maximum wall temperature variations were quite low with only $1.7 \%$ maximum error. Both the simulation and experiment results show that the temperature change from inlet to outlet is high for case 02 than case01. This indicates that carbon dioxide absorbs more energy at temperature higher than the pseudocritical temperature.

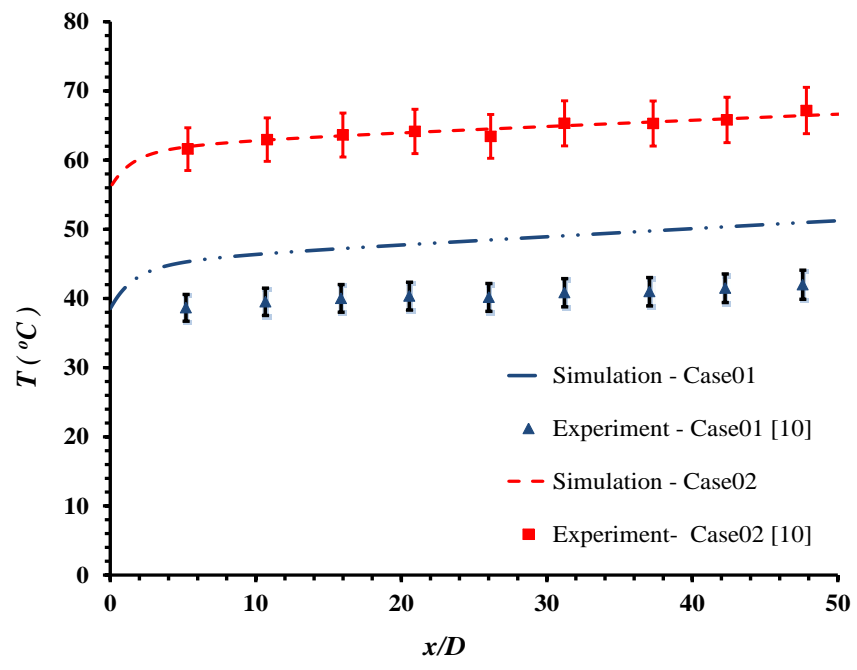

Fig. 2. Wall temperature versus diameter ratio for Case 01 and Case 02

Shown in Figure 3 is comparison of the heat transfer coefficient obtained from the current simulation results and experimental data from [11] for cases 01 and 02. As expected, the heat transfer coefficient $(\mathrm{h})$ decreased as the length to diameter ratio increased. This is due to the reason that a maximum and dominant convection heat transfer occurred at the entrance of the heated section of 
the pipe. The convection heat transfer raised the temperature inside the pipe, as well as mean temperature, along the downstream direction. This made the mean temperature near the exit to be higher relative to the entrance and therefore a lower convection heat transfer at the exit. As the heat transfer coefficient is function of temperature, similar trend of variations between the simulation and experimental results are observed, i.e., simulated heat transfer coefficient values are close to experiment for case 02 than 01 with $10 \%$ and $24 \%$ maximum errors. Since the Nusselt Number is a measure of convection heat transfer relative to conduction heat transfer. Thus from the results of heat transfer coefficient it is evident that the Nusselt Number will increase as the length to diameter ratio increases.

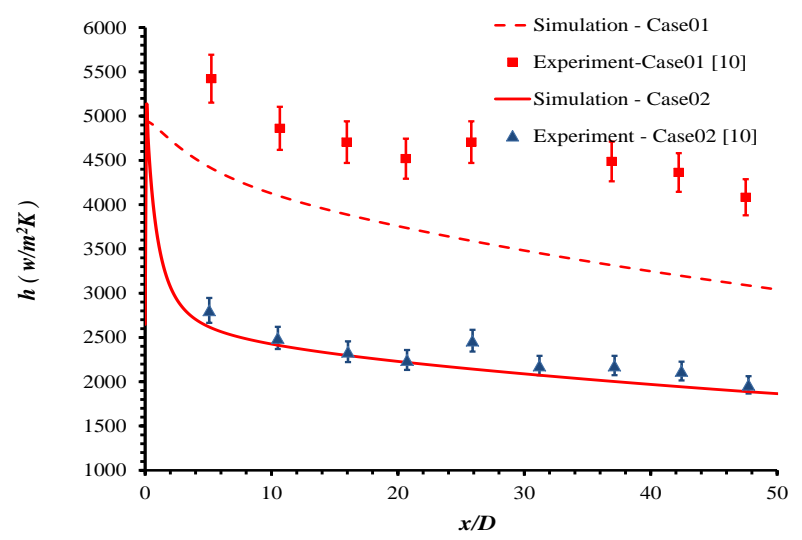

Fig. 3. Heat transfer coefficient (h) versus diameter ratio for Case 01 and Case 02

The pseudo-critical pressure and temperature for water are $22.07 \mathrm{MPa}$ and $374.4 \mathrm{oC}$ respectively. To examine the heat transfer coefficient variation for water at its supercritical phase, the parameters indicated in Table 2 are used. Since the critical temperature of water is high compared to $\mathrm{CO}_{2}$, higher heat flux was considered for the simulation.

Figure 4 shows variation of heat transfer coefficient (h) along the length of the heated tube at various inlet temperature values. Similar to the previous cases, the values of $h$ decrease as the length to diameter ratio increases. At near critical temperature, high value of $h$ is registered, on the other hand, as the temperature is far from the critical point, the $h$ values decrease significantly. The results show that the inlet temperature strongly affects the convection heat transfer at super-critical pressures. However, further simulations at various supercritical pressures need to be conducted to examine how pressures far from the critical point affect the convection heat transfer.

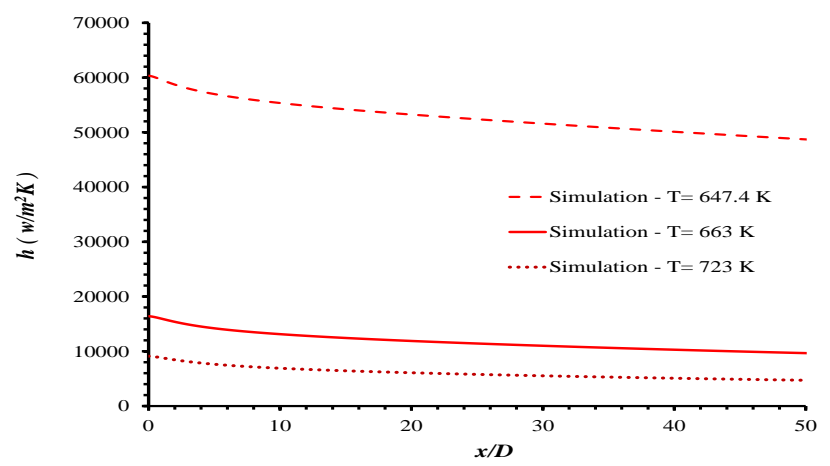

Fig. 4. Heat transfer coefficient (h) versus diameter ratio for supercritical water at various temperatures

\section{CONCLUSION}

Heat transfer during heating of turbulent flows of supercritical carbon dioxide and supercritical water was numerically investigated. The effects of inlet temperature on heat transfer process were analyzed. Using supercritical carbon dioxide as a working fluid, the heat transfer coefficient reaches a maximum for inlet temperature close to the pseudocritical temperature. As the inlet temperature is far from the pseudo-critical temperature, the heat transfer and change in wall temperature decrease significantly. Similar phenomena were observed for supercritical water at pseudo-critical pressure. Further studies need to be conducted to examine the effects of supercritical pressure, mass flow rate and flow orientation on the heat transfer rate for supercritical fluids.

\section{ACKNOWLEDGEMENT}

The authors would like to be obliged to Universiti Malaysia Pahang for providing laboratory facilities and Ministry of Higher Education Malaysia for financial assistance under FRGS project no. RDU130132.

\section{REFERENCES}

[1] J. M. Blackburn, D. P. Long, A. Cabañas and J. J. Watkins, "Deposition of conformal copper and nickel films from supercritical carbon dioxide," Science, vol. 294, no. 5540, pp. 141-145, 2001. DOI: 10.1126/science.1064148

[2] V. Chatoorgoon, "Stability of supercritical fluid flow in a single-channel natural-convection loop," International Journal of Heat and Mass Transfer, vol. 44 , no. 10 , pp. 1963-1972, 2001. DOI: 10.1016/S00179310(00)00218-0 
[3] V. Chatoorgoon, "Non-dimensional parameters for static instability in supercritical heated channels," International Journal of Heat and Mass Transfer, vol. 64, pp. 145-154, 2013. DOI: 10.1016/j.ijheatmasstransfer.2013.04.026

[4] L. Chen and X. R. Zhang, "Experimental analysis on a novel solar collector system achieved by supercritical $\mathrm{CO}_{2}$ natural convection," Energy Conversion and Management, vol. 77, pp. 173-182, 2014. DOI: 10.1016/j.enconman.2013.08.059

[5] S. C. Kim, J. P. Won and M. S. Kim, "Effects of operating parameters on the performance of a $\mathrm{CO}_{2}$ air conditioning system for vehicles," Applied Thermal Engineering, vol. 29, no. 11-12, pp. 2408-2416, 2009. DOI: $10.1016 /$ j.applthermaleng.2008.12.017

[6] J. Pettersen, A. Hatner, G. Skaugen and H. Rekstad, "Development of compact heat exchangers for $\mathrm{CO}_{2}$ airconditioning systems," International Journal of Refrigeration, vol. 21, no. 3, pp. 180-193, 1998. DOI: 10.1016/S0140-7007(98)00013-9

[7] M. A. Adams, E. O. Otu, M. Kozliner, J. Szubra and J. Pawliszyn, "Portable thermal pump for supercritical fluid delivery," Analytical Chemistry, vol. 67, no. 1, pp. 212-219, 1995. DOI: 10.1021/ac00097a032

[8] Q. Tao, Q. Wu and X. Zhang, "Thermal expansion pump for capillary high-performance liquid chromatography," Analytical Chemistry, vol. 82, no. 3, pp. 842-847, 2010. DOI: 10.1021/ac901855t

[9] S. Yoshikawa, R. L. Smith Jr, H. Inomata, Y. Matsumura and K. Arai, "Performance of a natural convection circulation system for supercritical fluids," Journal of Supercritical Fluids, vol. 36, no. 1, pp. 70-80, 2005. DOI: $10.1016 /$ j.supflu.2005.02.007

[10] I. L. Pioro, H. F. Khartabil and R. B. Duffey, "Heat transfer to supercritical fluids flowing in channelsEmpirical correlations (survey)," Nuclear Engineering and Design, vol. 230, no. 1-3, pp. 69-91, 2004.

[11] P. X. Jiang, Y. J. Xu, J. Lv, R. F. Shi, S. He and J. D. Jackson, "Experimental investigation of convection heat transfer of $\mathrm{CO}_{2}$ at super-critical pressures in vertical mini-tubes and in porous media," Applied Thermal Engineering, vol. 24, no. 8-9, pp. 1255-1270, 2004.

[12] A. Bruch, A. Bontemps and S. Colasson, "Experimental investigation of heat transfer of supercritical carbon dioxide flowing in a cooled vertical tube," International Journal of Heat and Mass Transfer, vol. 52, no. 11-12, pp. 2589-2598, 2009.

[13] H. Y. Gu, Z. X. Hu, D. Liu, H. B. Li, M. Zhao and X. Cheng, "Experimental study on heat transfer to supercritical water in $2 \times 2$ rod bundle with wire wraps," Experimental Thermal and Fluid Science, vol. 70, pp. 17-28, 2016.

[14] L. Zhang, M. Liu, Q. Dong and S. Zhao, "Numerical research of heat transfer of supercritical COR2R in channels," Energy and Power Engineering, vol. 03, no. 02, pp. 167-173, 2011.

[15] S. M. Liao and T. S. Zhao, "An experimental investigation of convection heat transfer to supercritical carbon dioxide in miniature tubes," International Journal of Heat and Mass Transfer, vol. 45, no. 25, pp. 5025-5034, 2002.

[16] T. Furlong, "A computational simulation of supercritical carbon dioxide and ethanol capillary flow," M. S. M. E. thesis, Mechanical and Industrial Engineering, University of Massachusetts, US, 2011.

[17] R. W. Shaw, T. B. Brill, A. A. Clifford, C. A. Eckert and E. U. Franck "Supercritical water: A medium for chemistry," Chemical \& Engineering News, vol. 69, pp. 26-39, 1991.

[18] S. Gupta, "Developing 1-D Heat Transfer Correlations for Supercritical Water and Carbon Dioxide in Vertical Tubes", thesis, University of Ontario Institute of Technology, Oshawa, Ontario, 2014.

[19] E. W. Lemmon, M. L. Huber and M. O. McLinden. (2007). NIST Reference Fluid Thermodynamic and Transport Properties-REFPROP. NIST Standard Reference Database 23, Ver. 8.0. Boulder, CO, U.S.: Department of Commerce.

[20] N. T. Rao, A. N. Oumer, and U. K. Jamaludin, "State-ofthe-art on flow and heat transfer characteristics of supercritical CO2 in various channels," The Journal of Supercritical Fluids, vol. 116, pp. 132-147, 2016.

[21] A. N. Oumer and O. Mamat, "A study of fiber orientation in short fiber-reinforced composites with simultaneous mold filling and phase change effects," Composites Part B: Engineering, vol. 43, pp. 1087-1094, 2012.

[22] A. N. Oumer and O. Mamat, "Numerical modelling of non-isothermal flow of fibre suspensions: prediction of fibre orientation in three-dimensional cavities " International Journal of Computational Science and Engineering vol. 9, 2014.

[23] A. N. Oumer, N. M. Hamidi, and I. M. Sahat, "Numerical prediction of flow induced fibers orientation in injection molded polymer composites," IOP Conf. Series: Materials Science and Engineering, vol. 100, 2015. 

— This article does not have any appendix.- 